\title{
Transfer of radionuclides to fruits: The activities of the biomass fruits working group
}

C.J. Atkinson, F. Carini ${ }^{1}$, C. Collins ${ }^{2}$, P.J. Coughtrey ${ }^{3}$, K. Eged $^{4}$, M.J. Fulker ${ }^{5}$, N. Green ${ }^{6}$, R. Kinnersley', 1. Linkov ${ }^{8}$, N.G. Mitchelf ${ }^{3}$ C. Mourlon ${ }^{9}$, Z. Ould-Dada ${ }^{10}$, J.M. Quinault', B. Robles ${ }^{11}$ A. Stewart ${ }^{2}$, L. Sweeck ${ }^{12}$ and A. Venter ${ }^{13}$

Crop Science Department, Horticulture Research International, West Malling, East Malling, Kent ME19 6BJ, U.K.

${ }^{1}$ Università Cattolica del Sacro Cuore, Faculty of Agriculfural Sciences, Institute of Agricuhtural and Environmental Chemistry, Via Emilia Parmense 84, 29100 Piacenza, Italy

${ }^{2}$ T.H. Huxley School of the Environment, Earth Resources and Engineering, Imperial College at Silwood Park, Ascot, Berkshire SL5 7TE, UK.

${ }^{3}$ Mouchel Consulting Ltd., West Hall, Parvis Road, West Byfleet, Surrey KT14 6EZ, U.K.

${ }^{4}$ Department of Radiochemistry, University of Veszpre $m$,

P.O. Box 158, 8201 Veszpré $m$. Hungary

${ }^{5}$ Environmental Sciences, Westlakes Scientific Consulting Ltd., Moor Row, Cumbria CA24 3LN, U.K.

${ }^{6} \mathrm{NRPB}$, Chilton, Didcot, Oxfordshire OX11 ORQ, U.K

${ }^{7}$ Division of Environmental Health and Risk Management, School of Geography

and Environmental Sciences, University of Birmingham, Edgbaston, Birmingham B15 2TT, U.K.

${ }^{8}$ Arthur D. Little Inc., 20 Acorn Park, Cambridge, MA 02140, U.S.A.

${ }^{9}$ Institute of Protection and Nuclear Safety (IPSN),

Division of Environmental Protection (DPRE), Laboratory of Environmental Modelling (LMODE),

CE Cadarache, 13108 Saint-Paul-lez-Durance cedex, France

${ }^{10}$ Food Standards Agency, Radiological Protection and Research Management Division,

Aviation House, 125 Kingsway, Room 715B, London WC2B 6NH, U.K.

${ }^{11}$ CIEMAT, Dept. de Impacto Ambiental (DIAE), Edif. 3A, Avenida Complutense 22,

28040 Madrid, Spain

${ }^{12}$ SCK-CEN, Boeretang 200, $2400 \mathrm{Mol}$, Belgium

${ }^{13}$ Enviros QuantiSci Ltd., Building D5, Culham Science Centre, Abingdon OX14 3DB, U.K.

\begin{abstract}
Given the potential radiological significance of the transfer of radionuclides to fruit, a Fruits Working Group was set up in 1997 within the framework of the Programme on BJOsphere Modelling and ASSessment (BIOMASS), promoted by the Intemational Atomic Energy Agency (IAEA) and in co-operation with the International Union of Radioecology (IUR). The aim of this working group was to improve understanding of the processes affecting the migration of radionuclides in fruit systems and to identify uncertainties associated with modelling the transfer of radionuclides to fruit. The main activities of the Fruts Working Group included: (i) a review of experimental, field and modelling in formation on the transfer of radionuclides to fruit; (ii) a derivation of a fruit conceptual model; (iii) a database of model parameters; (iv) a collection of additional information from experimental studies; (v) model intercomparison studies; and (vi) a validation study. This paper presents an overview of the main activities and results.
\end{abstract}

\section{ANTRODUCTION}

\subsection{Background}

Fruit, as a dessert component of the human diet, plays a considerable role in the global agricultural economy and makes a major contribution to the human diet, for some groups of the population. Fruits may become contaminated with radioactive material from nuclear facilities during routine operation, as a consequence of nuclear accidents, or due to migration through the biosphere of radionuclides from radioactive waste disposal facilities. 
Edible fruit is borne by different plant species, such as herbaceous plants, shrubs and trees, that can grow under different climatic conditions and may be found in agricultural or natural ecosystems. The transfer of radionuclides to fruit is complex and involves many interactions between biotic and abiotic components.

Radionuclides reach fruit by three principal routes: (i) deposition to soil, vertical migration in soil, root uptake, migration to the fruit (and other plant parts); and/or (ii) deposition to exposed plant surfaces, translocation to plant interior, migration to the fruit (and other plant parts); and/or (iii) deposition to exposed fruit surfaces. The relative significance of each pathway depends upon the season during which contamination occurs, the stage of plant development and upon how this development is affected by climatic, edaphic and management factors.

\subsection{History}

Until the inception of the Fruits Working Group, the potential radiological significance of the transfer of radionuclides to fruit was not well documented due to a lack of both qualitative and quantitative information on the behaviour of radionuclides in fruit bearing plants [1].

As a consequence a formal IUR Task Force on radionuclide transfer to fruits was established in late 1996 to promote interest in this subject. On the basis of the work completed by this Task Force, a Fruits Working Group was established as a joint IAEAIUR Co-ordinated Research Programme under IAEA's BIOMASS (BIOsphere Modelling and ASSessment) Theme 3 in September 1997. The objective of BIOMASS Theme 3 was to identify and attempt to solve issues of potential importance in biosphere model development and application. The activities of the Group were completed in November 2000. A final document (TECDOC) summarising the main achievements of the Fruits Working Group activities will be issued by the IAEA at the end of 2001 [2].

\subsection{Objective}

The objective of the FWG was to improve understanding of the processes affecting the transfer of radionuclides into and within fruit bearing plants. The main aim was to reduce the uncertainties associated with modelling the transfer of radionuclides to the fruit and thereby improve the robustness of models used for radiological assessment, and to increase the confidence with which these models can be applied. A combination of modeiling and experimental techniques was used to obtain maximum benefits from research and modelling.

This paper summarises the main activities carried out by the Fruits Working Group and the main results on the study of the transfer of radionuclides to fruit in the context of the overall objective of BIOMASS Theme 3 .

\section{ACTIVITIES OF THE BIOMASS FRUITS WORKING GROUP}

The FWG has been a collaborative effort that has brought together people and organisations from approximately 20 countries with common interests in modelling and experimental studies in the field of radionuclide transfer to fruits. A combination of theoretical and empirical techniques was used to obtain maximum benefits from experimental modelling. Researchers involved in related sciences have also been consulted in order to ensure that models of the Fruits Working Group, as well as the experimental data on which these models are based, consider ancillary knowledge from these related disciplines.

\subsection{The review}

A review of experimental, field and modelling information on the transfer of radionuclides to fruit was carried out at the inception of the activities of the Group, taking into account results of a Questionnaire circulated to radioecologists. The aim was to improve knowledge on the behaviour of radionuclides in soil-plant systems and in particular in fruit-bearing species. The review resulted in a substantial document, published in draft form by the IAEA as the first Working Document of the Fruits Working Group [3]. A further version was published as a Special Issue of the Journal of Environmental Radioactivity [4]. 
Given that this information has already been published, emphasis will be laid on new results from the Group's activities, reported in the following sections.

\subsection{Derivation of a conceptual model}

A systematic approach was taken by the participants to develop a conceptual fruit model and to assess the state of the participants knowledge for the dominant pathways. The objective was to identify gaps in knowledge of key processes and to provide guidance for future development of a conceptual model representing the contamination of fruit following atmospheric deposition. The approach used was adapted from the work of Avila and Moberg [5] on ${ }^{137} \mathrm{Cs}$ migration in forest ecosystems.

Eighteen participants, representatives from a broad range of interests and disciplines, contributed to the development of a matrix for the scenario of a fruit tree subject to a deposit from atmosphere (Figure 1), and attempted to arrive at a consensus on the key processes that determine the transfer of radionuclides to fruit. The relative importance of the interactions was scored and the ranked scores were used to produce a cause and effect relationship (Figure 2) and model structure diagrams. The state of knowledge of the Group about the highest-ranking interactions was also assessed qualitatively.

The diagram defines three important clusters (Figure 2). The Soil component shows that soils interacts strongly with the other components but is on balance subordinate to the rest of the system. The Air, Leaf and Wood \& Slem components show a weaker interaction with the system, compared to the Soil, but all of these are dominant components.

\begin{tabular}{|c|c|c|c|c|c|c|c|c|}
\hline Air & $\begin{array}{l}\text { deposition, } \\
\text { interception }\end{array}$ & $\begin{array}{c}\text { Deposition, } \\
\text { interception, } \\
\text { rainfall }\end{array}$ & $\begin{array}{c}\text { Deposition, } \\
\text { interception } \\
\text {, rainfall }\end{array}$ & $\begin{array}{c}\text { deposition, } \\
\text { interception, } \\
\text { rainfall }\end{array}$ & & & \begin{tabular}{|c|} 
deposition, \\
interception, \\
rainfall
\end{tabular} & $\begin{array}{c}\text { deposition, } \\
\text { interception, } \\
\text { rainfall }\end{array}$ \\
\hline resuspension & leaf & translocation & Wash-off & wash-off & & & $\begin{array}{l}\text { leaf-fall, } \\
\text { pruning }\end{array}$ & translocation \\
\hline resuspension & translocation & $\begin{array}{l}\text { Wood \& } \\
\text { stem }\end{array}$ & $\begin{array}{l}\text { Throughfall } \\
+ \text { stemflow }\end{array}$ & $\begin{array}{c}\text { throughfall + } \\
\text { stemflow }\end{array}$ & translocation & & $\begin{array}{l}\text { leaf-fall, } \\
\text { pruning }\end{array}$ & translocation \\
\hline resuspension & splash & splash & Soil & root uptake & root uptake & uptake & & resuspension \\
\hline \multirow[t]{3}{*}{ resuspension } & splash & splash & Migration & $\begin{array}{l}\text { Ground } \\
\text { cover }\end{array}$ & & - & $\begin{array}{l}\text { leaf-fall, } \\
\text { dieback }\end{array}$ & $\begin{array}{c}\text { splash/ } \\
\text { resuspension }\end{array}$ \\
\hline & & translocation & Exudation & $\begin{array}{l}\text { exudation, } \\
\text { root uptake }\end{array}$ & Roots & $\begin{array}{c}\text { exudate } \\
\text { transfer, } \\
\text { Michorhizza }\end{array}$ & dieback & \\
\hline & & & \begin{tabular}{|c|} 
Bioturbatio \\
$\mathbf{n}$
\end{tabular} & $\begin{array}{c}\begin{array}{c}\text { bioturbation, } \\
\text { excretion }\end{array} \\
\end{array}$ & $\begin{array}{c}\text { michorhizal } \\
\text { processes }\end{array}$ & Micro orgs & excretion & \\
\hline resuspension & resuspension & splash & Dissolution & $\begin{array}{c}\text { root uptake, } \\
\text { breakdown }\end{array}$ & & uptake & Dehris & resuspension \\
\hline Resuspension & Translocation & & fruit-fall & fruit-fall & & & wash-off & Fruit \\
\hline
\end{tabular}

Figure 1: Interaction matrix with 9 diagonal elements describing the migration and transfer of radionuclides within fruit trees following atmospheric contamination

The third cluster has the weakest interactions with the system and includes Ground cover, Roots, Microorganisms, Debris and Fruit. The role of micro-organisms remains uncertain; it is known they are important within the rhizosphere and on the phylloplane, but participants do not yet have a good understanding of these interactions. Micro-organisms could probably be incorporated within the root and 


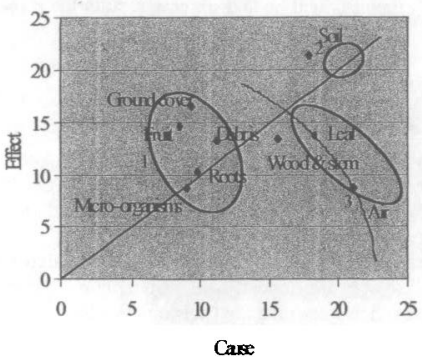

Figure 2: Cause effect diagram leaf elements without a major impact on the results obtained.

Results show where model development efforts should be directed and, combined with an assessment of the state of our knowledge for each of the interactions, can be used as a basis for assigning priorities for experimental work. It is clear from the cause-effect diagram that a model for fruit will need to concentrate on the interaction of Air, Leaf and Wood \& Stem with Soil as a subordinate component with the system. Although this is not an unexpected result for this scenario it has been reached through consensus and is based on a systematic analysis of the problem.

\subsection{The fruit parameter database}

The development of a database of model parameters for use in fruit models was one of the objectives of the Fruits WG activities. Participants provided data that have been incorporated into the RADFLUX database [6]. The database can be used to answer specific questions, to estimate missing data or model specific transfer parameters, and to provide an audit trail from model parameters to the underlying body of experimental data.

Although there is a large number of crops, 34, there are many for which there are only one or two records. 17 elements are represented, but there is a large bias towards data for caesium and strontium and the majority of data are soil-plant transfer factors that are not of great value in improving our understanding of the transfer to fruit, unless supported by additional information such as that required for RADFLUX entries.

\subsection{Recent completed or ongoing experimental studies}

Information has been collected and discussed from recently completed or ongoing experimental studies or from those not included in the Review. The aims were to collect information additional to that summarised in the Review, to improve knowledge of processes, and to provide data valuable either for the further development of models or for the testing and validation of existing ones. Information on the framework of completed studies is summarised in Table 1.

Table 1: Completed experimental studies

\begin{tabular}{|c|c|c|c|c|c|}
\hline $\begin{array}{l}\text { Institution/ } \\
\text { Person }\end{array}$ & Fruit & Nuclide & $\begin{array}{l}\text { Experimental } \\
\text { conditions }\end{array}$ & $\begin{array}{l}\text { Contaminat } \\
\text { ion }\end{array}$ & Endpoint \\
\hline $\begin{array}{l}\text { Imperial College } \\
\text { (UK) } \\
\text { C Collins }\end{array}$ & $\begin{array}{l}\text { Apple, raspberry, } \\
\text { strawberty, } \\
\text { blackcurrant }\end{array}$ & $\begin{array}{l}\mathrm{S}-35 \\
\mathrm{C}-14 \\
\mathrm{H}-3\end{array}$ & $\begin{array}{l}\text { Field } \\
\text { pots/Glass } \\
\text { house }\end{array}$ & $\begin{array}{l}\text { aerial/ } \\
\text { gaseous }\end{array}$ & $\begin{array}{l}\text { Rate constants for transfer to } \\
\text { leaves, fruit }\end{array}$ \\
\hline $\begin{array}{l}\text { IPSN } \\
\text { (France) } \\
\text { C Madoz-Escande }\end{array}$ & Vine & $\begin{array}{l}\mathrm{Cs}-137 \\
\mathrm{Sr}-90\end{array}$ & $\begin{array}{l}\text { Large-scale } \\
\text { lysimeters, } \\
\text { controlled } \\
\text { conditions }\end{array}$ & $\begin{array}{l}\text { aerial/dry } \\
\text { aerosol }\end{array}$ & $\begin{array}{l}\text { Measurements in time for three } \\
\text { years after deposition on: grape } \\
\text { (skin+seed, stalk, juice), wine, } \\
\text { shoots, leaves }\end{array}$ \\
\hline $\begin{array}{l}\text { Agricultural } \\
\text { University of } \\
\text { Athens (Greece) } \\
\text { G Arapis }\end{array}$ & Vine & Cs-134 & $\begin{array}{l}\text { Soil/field } \\
\text { conditions }\end{array}$ & $\begin{array}{l}\text { aerial /dry } \\
\text { aerosol }\end{array}$ & $\begin{array}{l}\text { First year: grapes from defoliated } \\
\text { or non-defoliated plants, covered } \\
\text { or non-covered grapes. Second } \\
\text { year results }\end{array}$ \\
\hline $\begin{array}{l}\text { Swiss Federal } \\
\text { Research Station } \\
\text { (Swiss) } \\
\text { H J Zehnder }\end{array}$ & Vine & $\mathrm{Cs}-134$ & $\begin{array}{l}\text { Hydroponic in } \\
\text { greenhouse }\end{array}$ & $\begin{array}{l}\text { droplets on } \\
\text { two leaves }\end{array}$ & $\begin{array}{l}\text { Measurements in time of } \\
\text { released Cs-134 and remaining } \\
\mathrm{K} \text { in the nutrient solution; Cs- } \\
134 \text { and } \mathrm{K} \text { uptake in the plant }\end{array}$ \\
\hline $\begin{array}{l}\text { NIRS (Chiba, } \\
\text { Japan) S Uchida }\end{array}$ & Apple, mandarin & $\mathrm{U}, \mathrm{Th}, \mathrm{Pb}$ & & soil & Washed fruit \\
\hline
\end{tabular}


New additional information from current experimental studies is being produced on apple, blackcurrant, blackberry, gooseberry, strawberry, olive, grapevine, mainly concerning caesium and strontium, but also plutonium, americium, iodine and cobait. Data that are going to be generated consider soil or leaf contamination and give concentration in different plant components, other than fruit, at ripening. Another set of data near to completion concerns caesium in strawberry components at different times after contamination. Information is also being collected from field measurements of Chernobyl fallout on sweet cherries, apricots, pears, apples, peaches and olives.

\subsection{Modelling}

The Fruits Working Group undertook two model intercomparison studies to identify and investigate significant areas of uncertainty and differences in approach between models. A validation study was also

Table 2: Participating models and model endpoints

\begin{tabular}{lll}
\hline Model & Developer/User & Model endpoint \\
\hline SPADE & $\begin{array}{l}\text { Ould-Dada, FSA (formerly MAFF), UK, } \\
\text { Mitchell, Mouchel, UK } \\
\text { Robles and Suanez, CIEMAT, Spain } \\
\text { FRUTI-CROM }\end{array}$ & $\begin{array}{l}\text { Conservative using best estimate parameters. } \\
\text { Activity and concentration in soil and plant. } \\
\text { Conservative using best estimate parameters } \\
\text { Probability distributions, conservative estimates } \\
\text { as 95 }\end{array}$ \\
RUITPATH & $\begin{array}{l}\text { Linkov \& Burmistrov, USA } \\
\text { Point estimates }\end{array}$ \\
DOSDIM & $\begin{array}{l}\text { Eged, Kis, Kanyar, Szederkenyi, } \\
\text { University of Veszorem, Hungary }\end{array}$ & $\begin{array}{l}\text { Deterministic and stochastic calculations } \\
\text { ASTRAL }\end{array}$ \\
\hline
\end{tabular}

undertaken where the models that participated in the model intercomparison studies were tested against an irdependent data set. Difficulties encountered by the Fruits Working Group in meeting this objective have been the lack of models specifically designed to model radionuclides in fruits and models designed for continuous releases. As a result several new models have been developed especially for fruits and some existing models have been extended. Other models have been adapted from modelling acute to continuous releases. The six models that participated in the modelling exercises are summarised in Table 2, along with their end points.

\subsubsection{Model intercomparisons}

Two scenarios were developed by the Group, one for acute and one for continuous releases. They reflected the interests of the Group participants in terms of fruit crops (apple, blackcurrant and strawberry) and radionuclides (Cs, $\mathrm{Sr}$ and $\mathrm{I}$ ). Only the graphs showing predictions for ${ }^{137} \mathrm{Cs}$ and ${ }^{90} \mathrm{Sr}$ in strawberry after acute deposition are reported here (Figure 3 ).

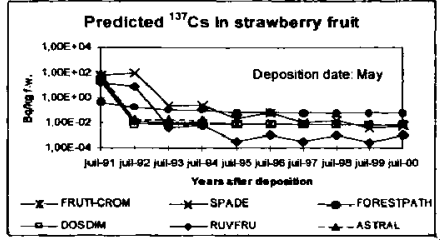

a)

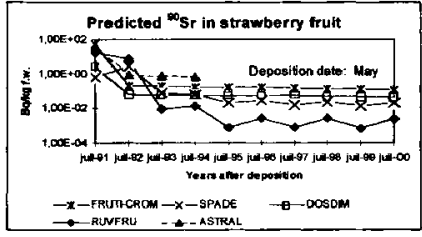

b)

Figure 3: Predicted ${ }^{137} \mathrm{Cs}$ (a) and ${ }^{90} \mathrm{Sr}$ (b) in strawberry fruit for an acute source term 
The variation between models was as high as five orders of magnitude for short-term predictions following the acute radionuclide deposition (Figure 3). For the long-term consequences and for the continuous deposition scenario, the differences between models decreased to only two orders of magnitude. A comparison of differences in the assumptions in the various models reveals that some of the processes are treated similarly by most of the models, while others are treated very differently.

The uncertainty for model parameters is in general larger for apples and blackcurrants than for strawberries. In addition fate and transport processes within blackcurrant bushes and apple trees are of greater complexity than those in strawberry plants.

The large differences among model predictions was greater than parameter uncertainty for any given model and reveals the current uncertainty in predicting future concentrations of radionuclides in fruits after contamination. Results clearly indicate the need for further development of models for the fate and transport of radionuclides in fruit ecosystems.

\subsubsection{Model validation}

A validation study was undertaken to test model predictions against an independent data set. One of the difficulties encountered has been the lack of data to validate study. The scenario is based on the transfer of ${ }^{134} \mathrm{Cs}$ and ${ }^{85} \mathrm{Sr}$ via leaf to fruit (at anthesis and ripening) and soil to fruit (at anthesis only) in strawberry plants after an acute release. Strawberry plants were grown in pots filled with peat substrate and placed under a ventilated tunnel in a field representative of horticultural growing conditions in Italy.

Only the graphs showing predicted and measured values for ${ }^{134} \mathrm{Cs}$ and ${ }^{85} \mathrm{Sr}$ after foliar contamination at ripening are reported here (Figure 4). Models performed reasonably well within the constraint of this particular scenario. In the case of foliar contamination (Figure 4), predicted values are generally in good agreement (within one order of magnitude) with the measured values, while in the case of soil contamination models tend to underpredict. Differences for caesium were up to three orders of magnitude greater for fruit and leaf, while differences for strontium were lower. Reasons of the underpredictions of models are probably related to the scenario interpretation.
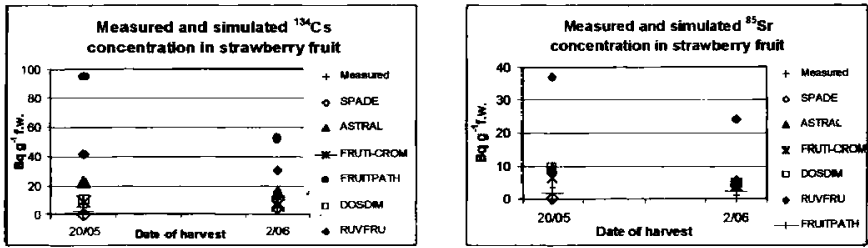

Figure 4: Measured and simulated concentrations of ${ }^{134} \mathrm{Cs}$ and ${ }^{85} \mathrm{Sr}$ (Bq $\mathrm{g}^{-1}$ fresh weight) in strawberry fruit after foliar contamination

\section{PRIORITIES FOR FUTURE WORK}

The activities of the FWG have resulted in several conceptual advances, new quantitative data and the development of models. Among the priorities for future work, model uncertainty analysis will help to identify parameters that have the largest uncertainty in model predictions, and identify areas where further work/research will be needed. Soil characteristics and short term processes have been identified as areas of great uncertainty that need to be reduced to improve the robustness of models that are used for radiological assessment.

In the wider context of the whole BIOMASS project, the main issue that needs to be addressed is the contribution of fruit to total dose to humans, in comparison to other exposure pathways. Future work will focus on those variables (radionuclides, fruits, pathways. fruit consumption, agricultural practices, climate) that can result in a dose to humans different from that resulting from other crops. Bearing in mind this object, the Fruits Working Group participants suggest that future activities include a reference crop in the 
fruit system, both in modeiling and, where practicable, in experimental studies. The reference crop will serve as analog where there is a lack of data on fruits, in order to model biosphere processes.

Information on priorities for further research and development of the models is reported in a final TECDOC that is going to be issued by the IAEA at the end of 2001 [2].

\section{Acknowledgements}

The authors are grateful to the UK Food Standards Agency (formerly MAFF) and the Environment Agency for England and Wales for financial support to the activities of the Fruits Working Group.

\section{References}

[1] Venter A., Coughtrey P.J., Carini F., Inoue Y., J. Envir. Radioac. 52 (2001) 117-122.

[2] International Atomic Energy Agency Transfer of Radionuclides to Fruit, TECDOC, BIOMASS Theme 3. Fruits Working Group (IAEA, Division of Radiation and Waste Safety, Vienna, in press).

[3] International Atomic Energy Agency, A Critical Review of Experimental, Field and Modelling Information on the Transfer of Radionuclides to Fruit. Working Document: BIOMASS/T3FM/WD01, (IAEA, Division of Radiation and Waste Safety, Vienna, 1999).

[4] Journal of Environmental Radioactivity. Special Issue: Radionuclide Transfer to Fruits: A Critical Review., P.J. Coughtrey Guest Editor, 52 (2001).

[5] Avila R. and Moberg, L., J. Environ. Radioactivity (1999). A Systematic Approach to the Migration of ${ }^{137} \mathrm{Cs}$ in forest ecosystems using interaction matrices.

[6] MITCHELL N.G. (1997). Development of an international radionuclide flux database: Progress Report January - June 1997. Mouchel Report No. 48146.001-TN1, October (1997) 